\title{
National Louis University
}

\section{Digital Commons@NLU}

Faculty Publications

Winter 2-26-2011

\section{A Temporal Model of Community Organizing and Direct Action}

Brad Olson

National-Louis University

Judah J. Viola,

National-Louis University

Suzette J. Fromm Reed

National-Louis University

Follow this and additional works at: https://digitalcommons.nl.edu/faculty_publications

Part of the Community Psychology Commons

\section{Recommended Citation}

Olson, Brad; Viola, Judah J.; and Fromm Reed, Suzette J., "A Temporal Model of Community Organizing and Direct Action" (2011). Faculty Publications. 50.

https://digitalcommons.nl.edu/faculty_publications/50

This Article is brought to you for free and open access by Digital Commons@NLU. It has been accepted for inclusion in Faculty Publications by an authorized administrator of Digital Commons@NLU. For more information, please contact digitalcommons@nl.edu. 
This is an Accepted Manuscript of an article published by Taylor \& Francis in Peace Review on February 26, 2011, available online: http://dx.doi.org/10.1080/10402659.2011.548253

A Temporal Model of Community Organizing and Direct Action

\author{
Brad Olson \\ National Louis University \\ Judah Viola \\ National Louis University \\ Suzette Fromm-Reed \\ National Louis University
}

Brad Olson is a community psychologist and assistant professor at National-Louis University in Chicago, IL. He is also an active member of Psychologists for Social Responsibility and cofounder of the Coalition for an Ethical Psychology. His research and action-related interests include nonviolence, community organizing, and human rights. E-mail: bradley.olson@nl.edu

Judah Viola is a community psychologist and assistant professor at National-Louis University in Chicago, IL. His research and advocacy interests involve promoting healthy communities and increasing civic engagement and prosocial behavior of individuals and groups within communities. E-mail: judah.viola@nl.edu

Suzette Fromm-Reed is a Community Psychologist and assistant professor at National-Louis University in Chicago, IL. Her research and evaluation interests involve health promotion throughout the community with a specific interest in mind-body health and fitness in girls. Email: Suzette.Fromm-Reed@nl.edu 
Psychology has much to contribute to engagement in community organizing and direct action. Such organizing and action is psychological: it is motivational, cognitive, attitudinal, and emotional. Psychological knowledge is a cost-free resource. It can be used to counter unjust power structures and their tendency to maintain policies and systems of social harm and inequality. A theoretical model of organizing and direct action that integrates knowledge from community psychology and related disciplines with historic and modern action campaigns is needed. Theory helps us learn from the past to guide us toward more effective future outcomes. A contemporary model of community organizing and direct action should achieve the following: be based on a search for informational truths, and bringing those truths out in the open, rather than merely demonstrating power through numbers or other means; assume multiple levels of involvement (such as individual, organizational, and community) and being responsive to multiple contexts; and accommodate the fundamental temporal nature of campaigns, including their oftentimes prolonged character and unexpected vicissitudes.

In terms of truth rather than power, social psychologists distinguish between informational and normative influence. Normative influence involves demonstrations of where a group stands and with what intensity it holds a position, as well as with how many members make up that group; it is not concerned with the content of the arguments.Marches and protests are largely indications of normative strength. Informational influence involves content, represented by the number and variety of arguments supporting or opposing a particular issue. Within informational campaigns, truth takes precedence, bringing out the best and fullest pool of arguments, emphasizing intellect and research to raise the consciousness of everyone involved with the decision.

Because they often occur over prolonged periods, campaigns based on informational influence frequently involve diverse situations. These diverse situational factors encountered require different responses, specific strategies most fitting with the particular context of the moment. This contextual, community psychology perspective is partially derived from past thinking in the field of non-violent 
action, which has tended to emphasize prescriptive philosophies or "rules," while simultaneously realizing such rules are too static to describe a dynamic campaign. Rules can lead to more effective campaigns, but are not to be understood as absolutes held constant regardless of changing contexts over time. A contemporary theory should capture the commonalities across different action campaigns, mapping general trends, and providing a practical guide. Yet the model simultaneously must be flexible enough to accommodate diverse, sometimes seemingly contradictory situations arising in past and future social action campaigns.

Two of the clearest explications of historical non-violent action orientations include Chicago organizer Saul Alinsky's rules for radicals and Gandhi's writings on non-violence. Alinsky’s Rule \#5, for instance, states that "ridicule" is the "most potent weapon." Through "ridicule," Alinsky believed that a silent, standoffish power structure may be—by being publicly told harsh or humiliating truths—coaxed into lashing back. This changes the power dynamics, and opens up new opportunities for both parties through dialogue and exchange. Gandhi held an opposite view. He believed that no action should ever insult or threaten the power structure. For Gandhi, non-violent action was rooted in a pure value system, which, though also a mode of non-violence, could be equally frustrating for the power structure and produce similar changes.

The differences in the philosophies are relevant to the design of the current model. A practical, contextualist temporal model of community organizing and action should incorporate and integrate varied philosophies. It should strive, for instance, toward applying Gandhi's values, while retaining many of the useful strategies described by Alinsky. Despite the theoretical differences across approaches to organizing and action, the core elements common to any campaign should be at the heart of a new model.

The temporal model introduced here is not a developmental or stage theory in which each process presented would appear in sequence during a campaign. Rather, this model is articulated through nine proposed processes, organized in a three-tiered system, which describes three core dimensions of campaigns. The first three processes describe initial, more preparatory aspects of a campaign: focusing, lever identification, and member gathering. The second three emphasize more psychological aspects: self- 
purification, empowerment, and critical kinship. The final three describe the more temporal (time-based) aspects, the iterative, continual recycling of actions over the existence of a campaign: dissemination, discovery-oriented dialogue, and iterative mobilization.

First, there is focusing - a need for those engaging in action efforts to locate a specific issue to tackle. Psychologically, people are more effective when goal-oriented. Every campaign must begin somewhere, and a common error of those wishing to see change is to conceptualize the aim too generally. The intent to change a large subset of the world, to eliminate homelessness, for example, is one naturally shared by many people. To achieve such a grand task takes time. One should think big and plan to act both locally and globally. Yet it is important to concentrate frequently on a single, concrete goal or focus. Viewing problems at a high level of abstraction creates challenges for planning, and becomes daunting as the nature of an overwhelming — and soon to be unorganized - task quickly becomes too much. Working toward a specific type of concrete change brings the attention and movement of diverse stakeholders toward a single aim.

The focusing process begins by identifying a disparity, a situation of injustice that simply should not exist and that evokes a sense of indignation, and then pinpointing the source of what feels "not quite right" or simply objectionable. Campaigns can exist with multiple goals that are clarified over time, but for each goal, it is important to begin by zeroing in on the specific target for action. Alinsky's Rule \#13 is: "Pick the target, freeze it, personalize it, and polarize it." Alinsky wanted to "personalize" individuals and groups for blame, but freezing or isolating issues is an essential and less polarizing and damaging process.

Second, a lever must be identified. Across a large campaign, multiple strategies and actions are used. Many of the rules and wisdom provided by Alinsky and Gandhi are mechanisms or psychological "levers" of change. There are also democratic mechanisms in the form of protest, legislative bills, referendums, and international conventions. Throughout a campaign, one will use all sorts of activities and approaches in sequence and in combinations. One often simultaneously concentrates on using a primary mechanism toward the focused issue (such as the ultimate goal). Means are as important as ends. Therefore, it is essential to remember that the levers chosen should be consistent in every way with the 
changes one wants to see in the world, and with the group's specific targeted goals. One wants to match the psychological lever(s) to the issue and to the general ethos of the campaign.

Third, members must be gathered. As human beings, we are psychologically attracted to likeminded others and to building networks. In an action campaign, we have to make a concerted effort to find those with potential interest in the issue at hand and then to help them understand the importance of the targeted goal or cause. An early step in an organizing/action campaign is to create a network of likeminded people to work together on the issue. The chances of success increase with more allies, particularly effective ones. Alinsky says that finding like-minded others is always the first step. Start with an existing network or use a snowball approach to build in size, discuss the issue with existing contacts, and ask, "Who else should I be contacting?" Engage in initial conversations with this new group of recommended individuals, often in individual meetings, or one-on-ones. Begin the focusing process with an initial network, and remain flexible in order to incorporate newcomers to the effort.

Social justice-oriented people frequently have common worldviews but also diverse interests and agendas. Varied interests within a coalition can work against a concentrated campaign. Everyone may agree to fight for "children's rights," but each person may have a different specific interest within the broad area of concern. Across the life of a campaign, many sub-issues more important to specific factions within the coalition can be addressed in one way or another. That does not mean they are part of the primary stream of the campaign. Also, the timing of when to focus on what aspect of the primary issue will depend on context, circumstance, and interest. Some social issues in certain time periods naturally and immediately evoke collective emotion and generate social cohesion. When a specific group is under threat through a particularly egregious form of legislation (such as anti-immigration legislation), there can be a natural readiness to react; in other situations, more work has to be done to achieve a real sense of unity and energy around the goal.

Fourth, self-purification must be accomplished. The prior three steps are important preparatory processes that incorporate psychological elements. The following three-self-purification, empowerment, and critical kinship - are almost exclusively psychological in nature. The most immediate psychological 
challenge in an action campaign lies with the self. Self-psychology, selfdetermination theory, and even the self-help aspect of psychology are critical in keeping organizers (and everyone else) engaged in a particular effort over the long-term. No matter how experienced one is, or how much confidence one has about being on the socially just side of an issue, there will always be self-doubts (about eventual success, whether one is on the right path, etc.) along the way. Inner conviction, which should not be confused with inflexibility, is essential to keeping highly engaged. Gandhi and prominent activists who followed in his footsteps believed a spiritual conviction and "pure motives" were a necessity. As he wrote, "Action demands the best of which one is capable, without reservations whatsoever."

Self-purification and sacrifice involve consistent self-directed reminders to focus on those who are most impacted by an issue and who continue to be the most vulnerable. Purification is about losing self and strongly empathizing with the situation of others. Standing up for one's own rights or taking on issues that are personally impactful is encouraged. Particularly in these cases, however, it is tremendously important to be introspective and have clear insight into one's own motives. Having clear and "pure" motives increases one's internal effectiveness (in terms of maintaining consistent motivation) as well as external effectiveness (not giving adversaries an easy way to discount one's arguments).

A continual struggle with the self is important because most campaigns are voluntary and thus require constant self-motivation and commitment to sustain active involvement. This is in contrast to engagement within a monetary economy, where extrinsic motivation propels the action. Telling others what to do and why it is worth doing only goes so far. Modeling action by personally taking part in all levels of tasks, drawing on deep personal engagement, is far more important than telling others what to do. These actions cannot be undertaken half-heartedly.

Fifth, empowerment is required. Psychology helps us understand ourselves and also others, their motivations, attitudes, and goals. Psychological knowledge is a probabilistic, and not absolute, form of knowing, although it can provide strong hints about the real world. Often that is enough. Understanding allies helps, such as knowing, for instance, whether they align with the effort because of empathy or 
political benefits or expectations of eventual reciprocity. It is useful to tease these motivations apart when possible.

We live in a world that is too often characterized by inaction. Too many people know too little about how to engage in social action. There is often an overwhelming pessimism, a learned helplessness, when it comes to the idea that even blatantly unjust power structures can be changed. Nothing releases people from the bonds of hopelessness, propelling them toward action, as does a sense of self- and collective-efficacy, an understanding that together they have the ability to reach desired goals.

The importance of self-efficacy comes from a tendency for people to lose or lack faith in other human beings, doubting that they can change or that humanity is even worth changing - the absence of what the psychologist Erik Erikson referred to as a "belief in the species." The confidence and faith Gandhi showed was remarkable, and was reflected in many of his wise words, such as: "When someone abandons truth, it is due to fear;" "Have calmness under fierce provocation;" and "Non-violence laughs at the might of the tyrant." He knew the ill effects negative emotionality could have, particularly to the authenticity and therefore the effectiveness of an effort.

Gandhi taught and epitomized resilience in the face of maladaptive emotions. Learned helplessness was inextricably linked to obedience training, and therefore hewarned against the subservience of ethics to legal frameworks: "Do not obey a law against one's conscience." He countered stereotypes of activists as anti-social, reversing such frames to emphasize their contribution to humankind: "An active resister is a philanthropist." Moreover, Gandhi strengthened a sense of efficacy by emphasizing the inevitability of success: “Given a just cause, victory is certain.” Transforming learned helplessness into self-efficacy releases the bonds to bring about social action. Within a social action campaign, this transformation is at the heart of the meaning of psychological empowerment and collective efficacy.

Sixth, there must be critical kinship. Gandhi explained, "Thieves must be led to realize the kinship." Gandhi uses a narrative of a thief to describe the attitude toward any "opposition." The goal is to get the thief to see the human bonds, the connection based on universality where strangers are equivalent 
to family, even a thief. The greatest distinction between Alinsky and Gandhi centers on differing ideas of how to perceive and interact with the opposition on any issue. The decisions around any active approach to a power structure may lead one to look for strengths in the other, engage in a critical attack, or try some synthesis of both. Alinsky's Rule \#5 is: "Ridicule is man's most potent weapon." This is in opposition to Gandhi's beliefs.Both weremaster tricksters, willing to break unjust laws, continually frustrating the power structure, and yet Gandhi negated the idea of ridiculing anyone, ever.

Alinsky demonstrates no shortage of egotism, boasting about his exploits, or lying. His promotion of deception is evident in his Rule \#1: "Power is not only what you have but what the enemy thinks you have." The idea of power through pleasure in puffery and dishonesty is fundamental. Gandhi argues, "Non-cooperation is not a movement of brag, bluster, or bluff." He says, "Conquer hate by love, untruth by truths, violence by suffering." This is about loving the enemy, being truthful, and purification of spirit. In contrast to ridicule as a weapon, Gandhi insists that not a negative thought or action should be taken against the power structure. One may not respect those who represent that structure, but one should never insult or allow the other side to feel threatened. When it comes to a campaign, there are times to force a wrench in the cogs of the system like Alinsky, but Gandhi knew well how to blend non-violent obstructionism (halting work and production throughout the whole of India, for example) with strengthsbased, humanity-affirming perceptions of the world. Because it is not driven by negative emotions and cognitions, it may also be more psychologically beneficial to the civil resister, and everyone else involved.

Alinsky's rules include several tactics targeting the unjust power structure. Requiring psychological knowledge of all stakeholders is his Rule \#2: "Never go outside the experience of your people and always go outside the experience of the other side." Rule \#4 states, "Make the enemy live up to their own book of rules." Every power-based organization has its policies, norms and precedents. Particularly when it comes to their own legally-binding policies, these entities take their own rules seriously. They tend to publicly do so only when it is to their own benefit. There is no greater lever than 
those rules, and using those rules to hold the power structure accountable, particularly when harms they precipitated violated those rules.

Different approaches work in different contexts of a campaign. Knowing the "other side" and synthesizing critical and strengths-based approaches can be most useful. Nevertheless, always trying to build a critical kinship is a good standard in any situation, at any point throughout a campaign.

Seventh, dissemination must also occur. While some of the prior processes are largely about lifting restraints and successfully generating actions, the following three processes-dissemination, discovery-oriented dialogue, and iterative mobilization — drive and maintain forward movement. Dissemination, the diffusion of information, is about letting the world know the problems at hand and the known facts around the issue. Knowing the facts requires research and well-crafted statements of many types, and then the distribution of that information through many forms of media and styles of communication. On the Internet, decisions are made about getting the information out on blogs, through open letters, e-mail lists, press releases, and other communicative methods. The choices depend on context. Strong communication networks develop, but communications should be paced depending on a particular group's tolerance for different styles and the sheer amount of information. A select few within an organizational effort may have the ability to tolerate near constant communications; others may require updates that are more widely paced over time.

Given the emphasis on informational influence in temporal campaigns, striving toward truth is paramount. Presenting arguments known from the whole pool allows the much wider group of stakeholders to decide where they stand. Organizing an action campaign on any issue is about education. It is about concentric circles of education: the self, allies, neutral parties, and those who seem to be opposing justice.

Eighth, there must be discovery-oriented dialogue. Despite diligent, intellectual work and research, unidirectional dissemination is insufficient for either engagement, truth-finding, or for eventual resolution. The temporal model is most of all about iterative functions. Each initiative, regardless of its primary target, has sub-goals. Iterative functioning simply means that over time, ideas about issues shift, 
new pieces of information emerge, investigations are ongoing, cyclical forms of work are done to narrow down the facts, as much as possible, to reach the actual truth. The use of information requires study, logic, awareness, and refinement. Resolution occurs through dialogue and negotiation. Continually, through dialogic exchange, the arguments and goals are further refined and an even more intense form of focusing occurs. In the back-and-forth between different sides, knowledge is acquired, and some of the possibilities for compromise occur.

Alinsky and Gandhi see things differently here too. Alinsky sees risks in such compromises. He warns against early counteroffers or "constructive alternatives" from the other side, particularly ones that soon follow a victory. Those in the power structure are often clever in the chess games of negotiations. Alinsky warns against being too pleased following a victory, and being hesitant to accept a counteroffer that falls short of the final goal. Alinsky's Rule \#12 warns, "The price of a successful attack is a constructive alternative." That constructive alternative, when offered by the other side, could detract from the final, ultimate justice-oriented prize. Action initiatives, however, rarely end this simply, with a single conclusive agreement. Even a policy change must be enforced, for instance. This is one of the reasons campaigns are enduring and that campaigners must have endurance.

Gandhi's approach to sharing information and compromise was that the whole effort of action, of "fighting," was that it was a new way for all sides to look at the situation. It is about all sides completely reframing the issue. Such dialogue never risks giving up the original goal. It is just a restructuring of how the activists and the power structure re-conceptualize the issue. Gandhi invited "constructive alternatives." For Gandhi, compromises were embraced, partially because he had complete efficacy—he never feared being dissuaded from the final goal, regardless of what smaller agreements were made along the way.

Ninth, iterative mobilization is required. The goal in any temporal action campaign is to keep things moving, to ensure a sustainable effort. Psychological obstacles among team members and allies can be created by poor leadership, confusion, misinterpretations of goals, boredom, forgetfulness, and much else. Such obstacles hamper movement and they can accumulate over time. There is nothing that breaks 
down barriers to open up channels like iterative, discovery-oriented dialogue. There are, however, other ways to increase the process of interest and engagement and to keep an effort by a coalition sustainable.

Four of Alinsky's thirteen rules for radicals are implicitly relevant to the sustainability of action across a campaign: "Keep the pressure on" (Rule \#8); "The major premise for tactics is the development of operations that will maintain a constant pressure on the opposition" (Rule \#10); "A tactic that drags on too long becomes a drag" (Rule \#7); and "A good tactic is one that your people enjoy" (Rule \#6). Many other rules can also contribute to sustainability, and to successes or small wins, as well as to transforming the original sense of indignation into a narrative of redemption. As Gandhi describes: "First they ignore you, then they laugh at you, then they fight you, then you win.”

As part of the temporal iterative process, it is important to encourage individual member initiative, and it becomes more and more important as the effort lasts and as endurance wanes. One should rarely discourage a group member who is filled with excitement about a particular path, if the intentions are good and if it is not simply self-serving. This is most true with a voluntary group: one cannot hold a coalition togetherwith a consistent “No, don't do that, don't go there." Mobilization is about channeling already existing directions of motivation and supporting, but only gently guiding, that movement.

One of the most vital mobilization rules that reinforces the earlier process of member gathering is to never underestimate the positive impact of friendships. In good campaigns, close friendships develop. If the campaign is all about friendships, even the most tedious forms of work do not seem like work at all. In between small wins, friendships, camaraderie, and intellectual challenges make it all worthwhile and invigorating. Friendships also provide checks and balances, forcing better decisions, better discoveryoriented dialogue, and better dissemination.

The purpose of developing the temporal model of organizing and direct action is to expand theoretical and scientific understandings of action while providing a practical guide to carrying out such actions. Alinsky's and Gandhi's particular approaches and emphases are two among many possible examples to illustrate the nature of this theory. There is much more to say and examine, theoretically and empirically about every process of this model, and how the whole relates to a variety of issues and 
dilemmas around social action. We hope the model will serve as a useful tool in understanding how psychology can be better used to bring about social change.

\section{RECOMMENDED READINGS}

Alinsky, Saul. 1971. Rules for Radicals: A Practical Primer for Realistic Radicals. NewYork: Vintage.

Brown, Roger. 1986. Social Psychology. New York: The Free Press.

Freire, Paulo. 2007. Pedagogy of the Oppressed. New York: Continuum.

Gandhi, Mohandas. K. 1951. Non-Violent Resistance. New York: Shocken.

Rappaport, Julian. 1977. Community Psychology: Values, Research, and Action. New York: Holt, Rinehart, and Winston.

Rubin, Herbert J. and Irene S. Rubin. 2008. Community Organizing and Development. Boston, MA: Pearson. 